\title{
Da criação de espaços de dizer: (re)normalizações e usos de si no trabalho
}

\section{On creating speech-spaces: (re)normalization and the uses of self in work}

\author{
Ivete Bellomo MACHADO* \\ Instituto Federal Sul-Rio-Grandense (IF-SUL) \\ Maria da Glória Corrêa DI FANTI** \\ Pontifícia Universidade Católica do Rio Grande do Sul (PUC-RS)
}

\begin{abstract}
RESUMO: Devido à importância do trabalho na sociedade contemporânea e à sua relevante e complexa relação com a linguagem, faz-se necessário desenvolver pesquisas focalizando a interface linguagem e trabalho sob o ponto de vista da atividade humana. Tomando como base teórica a perspectiva dialógica da linguagem em interlocução com os estudos ergológicos, buscamos, neste artigo, verificar aspectos do debate de normas e dos usos de si na atividade do trabalhador de uma empresa comercial. Como procedimentos metodológicos, criamos espaço de fala aos trabalhadores a partir de entrevistas individuais, as quais suscitam reflexões sobre a atividade realizada. Desse material, foram selecionados para a análise enunciados de dois trabalhadores entrevistados. Com esta investigação, buscamos contribuir para o (re)conhecimento da atividade laboral, levando em conta a complexidade das relações que se efetivam nesse espaço.
\end{abstract}

PALAVRAS-CHAVE: Perspectiva dialógica. Abordagem ergológica. Atividade de trabalho.

ABSTRACT: Due to the importance of work in contemporary society and its relevant and complex relationship with language, it is necessary to develop research focusing on the interface language and work based on the point of view of human activity. Based on the theoretical dialogical perspective of language in dialogue with ergologic studies, we intend in this article to verify aspects of the debate of norms and the uses of oneself in the activity of the employee of a trading company. As methodological procedures, we create speech-space to workers according to individual interviews, which instigate reflections about the performed activity. Using this material, enunciations of two interviewed workers were selected to the analysis. With this research, we aim to contribute to the (re)cognition of laboral activity, taking into consideration the complexity of the relationship that takes action in this space.

KEYWORDS: Dialogic perspective. Ergological approach. Work activity.

\footnotetext{
* Doutorado em Letras (Linguística Aplicada); professora do Instituto Federal de Educação, Ciência e Tecnologia Sul-Rio-Grandense (IF-SUL) - campus Pelotas/Visconde da Graça. Pelotas - RS - Brasil. Email: ivebell@hotmail.com.

** Doutorado em Linguística Aplicada e Estudos da Linguagem; professora da Pontifícia Universidade do Rio Grande do Sul (PUC-RS), Departamento de Estudos Linguísticos e Programa de Pós-Graduação em Letras da PUC-RS. Porto Alegre - RS - Brasil. E-mail: gdifanti@gmail.com.
} 


\section{Considerações iniciais}

Este artigo, desdobramento de uma pesquisa maior ${ }^{1}$, problematiza a atividade de trabalho em uma empresa de médio porte, situada no interior do Rio Grande do Sul, que comercializa parafusos e material de ferragem. Nossa inserção nesse espaço laboral deu-se, principalmente, devido a uma demanda da própria empresa, cujo teor foi especificado como falta de envolvimento do trabalhador com a atividade que realiza.

Partindo da demanda apresentada, passamos a nos interrogar sobre de que modo deveríamos intervir a fim de colaborar com a investigação. Necessitamos, para tanto, de nos inteirarmos de aspectos do contexto da empresa, que, nos últimos tempos, teve um relevante crescimento em termos de abrangência: aumento da cartela de produtos comercializados, de cidades assistidas e de clientela (varejo e atacado). Com a expansão, aumentou também o número de funcionários e as atividades se diversificaram, sendo necessário criar novos setores e novos cargos para os trabalhadores. Diante desse cenário e considerando a demanda da empresa, emergiram alguns questionamentos: A empresa promove aos trabalhadores algum espaço de discussão sobre o seu próprio fazer? Qual a perspectiva dos trabalhadores em relação a sua atividade de trabalho? Como o trabalhador enfrenta o dia a dia de trabalho? Se o trabalhador é visto pelo empresário como alguém que não se envolve com a atividade laboral, o que poderíamos fazer como pesquisadores, ou ainda, a que recursos poderíamos recorrer do ponto de vista teórico e metodológico que pudessem iluminar a questão?

Dois eixos centrais se articulam para responder a essa demanda: a linguagem, sob o viés da perspectiva dialógica, e o trabalho, sob o viés da abordagem ergológica. Esses dois enfoques têm como questão central a atividade humana, considerada em suas complexas e opacas relações de sentido. Pela perspectiva adotada, a análise de práticas de linguagem é fundamental para criar conhecimento sobre atividades distintas de trabalho. Destacamos, nessa direção, a necessidade de uma concepção de linguagem pautada na alteridade, como é o caso da perspectiva bakhtiniana, para abordar o trabalho como atividade (DI FANTI, 2012).

O trabalho, para a abordagem ergológica, é uma atividade industriosa, enigmática, que causa desconforto intelectual ao pesquisador ao sempre ser renormalizada, isto é, variar em diferentes graus. Essa variabilidade, por menor que seja, revela a infidelidade do meio, que não permite uma simples repetição. Considerado uma alquimia indefinida, o trabalho humano, ao ser problematizado, pode contribuir para a reflexão de dada prática profissional, constituída pela tensão entre o visível e o invisível (SCHWARTZ, 2011; SCHWARTZ, DURRIVE, 2010).

Essa tensão convoca questionamentos sobre a atividade de trabalho, em geral, e do trabalho na empresa em foco em particular. Visando a uma aproximação à cultura do trabalho, temos buscado intervir no meio social do pesquisado, de modo a fazer emergir aspectos da experiência e do saber-fazer do trabalhador (FAÏTA, 2003; SCHWARTZ, 2011; HINZ, DI FANTI, 2012). Nessa direção, com o respaldo da teoria bakhtiniana e da ergologia, temos o objetivo, neste artigo, de verificar aspectos do debate de normas e dos usos de si na atividade do trabalhador.

Para que uma atividade se realize, há a necessidade de normas antecedentes, entretanto somente elas não são suficientes, diante das infidelidades do meio e da

\footnotetext{
${ }^{1}$ Este artigo é um desdobramento de parte da tese de Ivete Bellomo Machado (2012), defendida no Programa de Pós-Graduação em Letras da Universidade Católica de Pelotas, sob a orientação da Profa. Dra. Maria da Glória Corrêa di Fanti.
} 
singularidade de cada situação. Assim, há um apelo a um uso de si por si, ou seja, o trabalhador lança mão de sua experiência, de seus valores, para fazer escolhas e suprir a deficiência das normas. Além disso, o outro está também presente nessas arbitragens, mas não apenas com a presença física de alguém. “Os outros”, segundo Schwartz (2007, p. 193), "é uma noção que remete a conjuntos de estatutos muito diversos e, de uma certa maneira, muito obscuros”, pois eles estão presentes das mais variadas formas, seja através das prescrições, seja através dos valores coletivos do espaço laboral, seja através das próprias infidelidades do meio. Desse modo, há um debate de normas constante em que o trabalhador faz uso de si por si e pelo outro (SCHWARTZ, 2002, 2006, 2007).

Como procedimentos metodológicos, procurando criar espaços de fala aos trabalhadores, realizamos entrevistas individuais aos funcionários que se dispuseram a participar da pesquisa. ${ }^{2}$ Das entrevistas realizadas, no total de oito, selecionamos discursos produzidos por dois entrevistados, tendo como critério o seu lugar de trabalho: o setor de estoque. Esse setor nos chamou atenção pela dinamicidade das atividades ali desenvolvidas e pela sua importância para toda a empresa, uma vez que dele dependem outros setores, como as vendas internas, as vendas externas e as televendas.

Para o desenvolvimento desta reflexão, apresentamos o referencial teórico e, na sequência, o detalhamento da metodologia e a análise do material selecionado. Nas Considerações finais, discorremos sobre características das atividades desenvolvidas pelos trabalhadores entrevistados, buscando contribuir para o (re)conhecimento da complexidade da atividade laboral em pauta.

\section{Linguagem e o trabalho: tessituras teóricas}

Nesta seção, são apresentadas reflexões sobre a linguagem, a partir da teoria bakhtiniana, e sobre o trabalho, a partir da abordagem ergológica, procurando levantar noções e conceitos produtivos para essa aproximação.

\subsection{Perspectiva dialógica da linguagem}

A linguagem, para a teoria bakhtiniana, é considerada essencialmente dialógica, já que se constitui de modo inter-relacional, como uma resposta no diálogo social. Essa resposta ativa se dá tanto em relação a enunciados passados como em relação a enunciados futuros, antecipação de resposta, tendo em vista a projeção a um interlocutor também ativo (BAKTHIN, 1997, 2006a). Sendo inseparável do fluxo da comunicação verbal, a língua não se transmite, mas dura e perdura num processo evolutivo contínuo, daí seu caráter dinâmico e heterogêneo: "a língua constitui um processo de evolução ininterrupto, que se realiza através da interação verbal social dos locutores” (BAKHTIN;VOLOCHÍNOV, 2009, p. 132, grifo do autor).

O enunciado, entendido como elo e unidade mínima na cadeia de comunicação discursiva, instaura-se como uma complexa rede de relações com o outro, nem sempre aparentes. Se enunciar é responder a enunciados e a sujeitos, o mesmo se pode dizer da compreensão. Comprender também é responder ou, ainda, atribuir contrapalavras a outros enunciados, a outros sujeitos (BAKHTIN; VOLOCHÍNOV, 2009; BAKHTIN, 2006a, 2006b).

\footnotetext{
${ }^{2}$ Em reunião realizada na empresa, apresentamos nosso projeto de investigação e solicitamos voluntários para a pesquisa. Oito trabalhadores se apresentaram e participaram de entrevistas individuais feitas na própria empresa. Além das oito entrevistas, realizamos duas observações de campo: uma no setor de estoque; outra no setor das televendas.
} 
Desde as primeiras obras de Bakhtin, como é o caso de Para uma filosofia do ato responsável (2010), a linguagem é considerada, segundo Faraco (2009, p. 23-24), “como atividade (e não como sistema)", sendo o enunciado entendido "como um ato singular, irrepetível, concretamente situado e emergindo de uma atitude ativamente responsiva". Dada sua singularidade, conforme Bakhtin (2010), não há como prever as condições de sua realização; elas são únicas e dependem de vários fatores (condições do meio, relações interpessoais etc.), fazendo com que cada um enfrente de um modo os riscos que a situação oferece. Esse enfrentamento está correlacionado à responsabilidade.

O pensador russo reforça que "não é o conteúdo da obrigação escrita que me obriga, mas a minha assinatura colocada no final”, ou seja, é o sujeito que pode decidir se se compromete ou não. E, quando ele realiza esse ato, o aspecto do conteúdo apenas o constitui, mas o que o decide é o reconhecimento ou afirmação - a ação responsável - que tinha sido realmente realizada anteriormente. A unidade constante de responsabilidade aparecerá em toda parte, isto é, o "fato real de reconhecimento, singular e irrepetível, emotivo-volitivo e concretamente individual” (BAKHTIN, 2010, p. 94). O tom emotivovolitivo representa

exatamente o momento do meu ser ativo na experiência vivida, o vivenciar a experiência como minha [...] Este relacionar a experiência a mim como ativo tem um caráter valorativo-sensorial e volitivo-realizador e é, ao mesmo tempo, responsavelmente racional (BAKHTIN, 2010, p. 91).

A responsabilidade é, portanto, ativa e encontra suas origens tanto na emoção, quanto na vontade do sujeito.

O ato, para o pensamento bakhtiniano, é responsável, pois, sendo de autoria de um sujeito, não há como ter álibi, não há isenção de participação. Da mesma forma, todo ato enunciativo, como o discurso - a língua em sua integridade concreta e viva - é de responsabilidade de um sujeito. É justamente o discurso e suas relações dialógicas ou, mais precisamente, o enunciado concreto e suas múltiplas relações de sentido, que são objeto de reflexão da translinguística, arcabouço teórico-metodológico bakhtiniano (BAKHTIN, 1997). ${ }^{3}$

De acordo com a teoria dialógica, o discurso de cada um é povoado de outras vozes, pontos de vista, visões de mundo, resultantes de sua história, sua experiência, seus valores. Na constitutiva relação eu/outro, os enunciados materializam-se por signos interrelacionais, dinâmicos, o que configura variadas relações e correlações em situações concretas. A linguagem, nessa perspectiva, é uma atividade bastante complexa. Ao colocar em palavras o que se pretende dizer, o que se faz é expor um olhar, a perspectiva de quem está formulando o enunciado. No entanto, não se tem controle absoluto sobre o dizer, já que nunca se diz tudo o que se queria dizer, e o que é dito mostra e esconde outros dizeres (BAKHTIN, 2006a; DI FANTI, 2012).

A palavra, signo ideológico por excelência, não só reflete mas também refrata uma dada realidade. Como a palavra faz parte de um território comum entre os interlocutores, ela não é propriedade exclusiva de ninguém. Seu território é sempre de fronteira, uma vez que seus valores são determinados pelas experiências sociais, que estão em constante movimento na expressão do vivido (BAKHTIN; VOLOCHÍNOV, 2009). Não há a primeira palavra, a fundadora, pois somos todos povoados de vozes, e é essa multiplicidade de vozes que nos constitui como sujeitos dialógicos e constitui a singularidade do nosso discurso (BAKHTIN, 1993; FARACO, 2009).

\footnotetext{
${ }^{3}$ Sobre a translinguística, consultar Di Fanti (2012).
} 
Relacionando a interação verbal, a valoração e o contexto, Bakhtin (1992, p. 313, grifo do autor) observa que "a palavra existe para o locutor sob três aspectos: como palavra neutra da língua e que não pertence a ninguém; como palavra do outro pertencente aos outros e que preenche o eco dos enunciados alheios; e, finalmente, como palavra minha". Essa última dimensão implica a minha avaliação, o tom avaliativo, "pois, na medida em que uso essa palavra numa determinada situação, com uma intenção discursiva, ela já se impregnou de minha expressividade”. Essa reflexão remete à importância de se observar a palavra na enunciação concreta, já que seu sentido é atualizado no evento do ato, expressando um juízo de valor do locutor em relação ao interlocutor e ao(s) outro(s). Nesse processo, como observa Bakhtin (2006b, p.333-334), a palavra, ao ser acentuada valorativamente, entra no diálogo e "quer ser ouvida, entendida, respondida e mais uma vez responder à resposta, e assim ad infinitum", pois "para a palavra (e consequentemente para o homem) não existe nada mais terrível do que a irresponsividade".

Segundo Bakhtin (2006c), o eu se constitui em constante diálogo com o outro, age em direção ao outro, levando em conta suas opiniões, seus saberes e seus valores, seja para concordar com eles seja para confrontá-los com os próprios. A relação de alteridade (eu/outro), que está na fundamentação do dialogismo bakhtiniano, mostra o inevitável envolvimento com o outro. Entretanto, cada um é único, não podendo ser substituído pelo outro na sua responsabilidade, pois cada um é insubstituível, constituído singularmente nas relações estabelecidas com o outro (BAKHTIN, 2010).

Cada enunciado particular é individual, pois é produzido por um locutor em relação a um interlocutor em dada situação concreta. No entanto, cada campo de utilização da língua elabora seus tipos relativamente estáveis de enunciados, os quais são denominados de gêneros do discurso (BAKHTIN, 1997, 2006a). Isso significa que o emprego da língua efetua-se em forma de enunciados, concretos e únicos, proferidos pelos integrantes de dada esfera da atividade humana. Pela teoria bakhtiniana, entende-se que todas as atividades humanas estão relacionadas ao uso da linguagem, instituindo uma relação indissociável entre esfera, gênero e enunciado. Daí a importância de se analisar práticas de linguagem para se ter acesso a espaços sociais, como é o caso de esferas de atividade de trabalho.

\subsection{Abordagem ergológica do trabalho}

Quanto aos estudos sobre o trabalho, nesta reflexão, optamos pela abordagem ergológica, que concebe o trabalho como um objeto complexo a partir da atividade concreta de quem trabalha. O ponto de partida é a distância apontada pela ergonomia da atividade entre trabalho prescrito e trabalho efetivamente realizado. A ergologia, por sua vez, amplia os conceitos da ergonomia da atividade e se utiliza de outras disciplinas (como filosofia, linguística, sociologia, psicologia, medicina do trabalho e engenharia de produção) para poder compreender a complexidade do trabalho. Do ponto de vista ergológico, o trabalho é a atividade de seres humanos situados no tempo e no espaço e que se dá no acontecendo da vida. São atividades sempre complexas e que possuem um caráter enigmático (SCHWARTZ, DURRIVE, 2010).

Os estudos ergológicos entendem a atividade de trabalho como uma dramática de usos de si: uso de si por si e uso de si pelo outro. Essa atividade possibilita negociação entre normas antecedentes, que regulam o fazer, e renormalizações decorrentes da inscrição do sujeito na atividade. O ambiente de trabalho torna-se então um espaço de tensões problemáticas, de negociações de normas e de valores, daí considerá-lo um drama para um corpo-si, uma entidade enigmática, que indissocia o corpo físico e a mente, abrangendo interações sociais, memória, emoções, posição postural etc. Nessa dramática, é 
preciso usar saberes práticos para poder lidar com a imprevisibilidade inerente ao exercício profissional (SCHWARTZ, 2002, 2006, 2007).

Quando o indivíduo tem a clareza de que a vida é renormalizada de forma permanente, a cada atividade, no cotidiano, ele pode perceber a sua possibilidade de negociar nos espaços coletivos de trabalho, aprendendo com a experiência, colocando questões e antecipando problemas a serem resolvidos. Daí o sujeito poder atribuir importância à sua própria história, vendo-se como alguém que participa dela e é capaz de (co)construí-la (MACHADO, 2012).

Se as condições históricas são um já-dado (normas), o trabalho efetivamente realizado (assim como a vida) nunca é apenas isso, pois o humano não só varia, mas produz variações. Nesse sentido, as pessoas praticam, o tempo todo, uma gestão de si como uma questão humana que envolve escolhas, valores, arbitragens. A gestão é da ordem da vida.

Ao fazer uso de si, o trabalhador arrisca e pode falhar. Isso se dá devido à dinamicidade da vida, mediante a qual estamos constantemente correndo riscos, podendo acertar ou errar. Nesse trabalho como uso, o outro participa tanto no contato direto e real quanto nas nossas decisões, pois, no momento em que escolhemos um caminho, ele nada mais é do que uma resposta ao que já vimos outros fazerem ou por aquilo que esperamos ouvir de outros. É preciso buscar esse uso de si por si onde se encontram forças aliadas, afirmadoras da vida; é aí que o sujeito lança mão de si mesmo para solucionar seus dilemas, sendo, por isso, responsável por suas decisões e arbitragens. No microcampo da dramática do uso de si, no acontecendo do trabalho, não há como se alienar do próprio uso de si. (SCHWARTZ, 2007).

Para a abordagem ergológica, o trabalho "sempre comporta uma parte invisível ou uma penumbra”, o que significa dizer que há uma dimensão incontornável, não apreendida. No dizer de Schwartz, a atividade de trabalho possui "um nó de debates entre normas antecedentes e tentativas de renormalização", que põe em jogo diferentes valores, saberes e experiências (SCHWARTZ, 2011, p.31, 34). Se, no meio social, em geral, as interações envolvem tensões, angústias, expectativas e desafios, no meio laboral, em particular, esses sentimentos podem se potencializar, nas diversas interações com o outro (em sentido amplo) que, de algum modo, atravessa a atividade do trabalhador.

Em função de a atividade de trabalho ser considerada complexa, diferentes estudiosos, como é o caso de seguidores da ergologia, têm observado a importância de se criar espaço de fala para o trabalhador refletir sobre sua experiência (DI FANTI, 2012). No caso das ciências da linguagem, há que se considerar que, por um lado, a linguagem é constitutiva do trabalho, e, por outro, é reveladora do trabalho. Para Nouroudine (2002), há três dimensões indissociáveis da linguagem: como trabalho (operante), no trabalho (circundante; engloba uma situação mais ampla) e sobre o trabalho (que interpreta). Tendo em vista uma busca de aproximação entre os saberes da academia e os da experiência laboral, faz-se necessário proporcionar espaços de dizer para o trabalhador falar sobre o seu trabalho (na imbricação no e como trabalho), fazendo emergir reflexões sobre a própria experiência laboral ${ }^{4}$.

Falar sobre o trabalho é uma possibilidade de trazer à tona, ainda que parcialmente, o que não é visível na atividade real. O espaço laboral é rico em interações e,

\footnotetext{
${ }^{4}$ Diferentes metodologias, filiadas a variados grupos (Analyse Pluridisciplinaire des Situations de Travail (APST), Grupo Ergonomie de l'Activité des Professionnels de l'Éducation (ERGAPE), Clínica da Atividade etc.), têm sido desenvolvidas, visando à reflexão do trabalhador sobre o seu fazer, como é o caso da autoconfrontação que, em termos gerais, proporciona a observação da atividade realizada, no sentido de fazer emergir pelo discurso aspectos do real da atividade (não observável) (FAÏTA, 1997, 2005; CLOT, FAÏTA, 2000; CLOT, 2010).
} 
consequentemente, pleno de conflitos. Para que ao menos se iluminem esses conflitos, é preciso ouvir o trabalhador, abrindo espaços de dizer para que ele possa discutir sobre sua atividade laboral e suas relações quase sempre problemáticas nesse meio. Há muitos embates no envolvimento de cada sujeito com o outro e com a própria atividade; são várias opiniões, muitas experiências que se cruzam, algumas angústias e tensões que se criam, enfim, há uma complexidade em transformação. O trabalhador, nesse sentido, precisa refletir constantemente sobre o que faz, ou seja, ele necessita observar-se, questionar-se, tentando entender seu papel no meio laboral em que está inserido para poder se envolver com as suas atividades e se sentir integrado no ambiente de trabalho (MACHADO, 2012).

Tendo em vista os pressupostos teóricos, que respaldam esta reflexão, passamos a apresentar os procedimentos metodológicos e a análise do material selecionado para este artigo.

\section{Linguagem e trabalho: tessituras analíticas}

\subsection{Da instauração de espaço de dizer}

Além da observação das situações de trabalho na empresa comercial, em dois momentos de duas horas cada uma, realizamos entrevistas com os trabalhadores que se dispuseram a participar da pesquisa. As entrevistas surgiram como um espaço de dizer para que os trabalhadores da empresa pudessem refletir sobre a sua atividade de trabalho, a partir da provocação do interlocutor, no caso a pesquisadora, em situação de entrevista.

A entrevista, nesta reflexão, é considerada um gênero do discurso, com um projeto enunciativo definido, em que tanto o entrevistador quanto o entrevistado têm papel ativo na interação. É um campo de circulação de determinados discursos, não sendo entendida, portanto, como mero instrumento de captação de um dito (ROCHA, DAHER, SANT’ANNA, 2004). Nessa direção, consideramos como condição a posição exotópica dos interlocutores (entrevistador e entrevistado), que evidencia a diferença dos lugares ocupados (BAKHTIN, 1992, 2006a).

Realizamos entrevistas semiestruturadas, individuais, em profundidade, em que buscamos, sobretudo, criar uma situação em que o entrevistado se sentisse à vontade e discorresse sobre o tópico em questão: a atividade laboral na empresa em que trabalha (MACHADO, 2012). As entrevistas, entre 20 e 50 minutos, foram efetuadas em uma sala própria para reuniões na empresa. Foram entrevistados oito trabalhadores, dos quais quatro pertenciam ao setor de estoque, espaço central para a empresa.

Do material oriundo das entrevistas, selecionamos para análise, neste artigo, discursos de dois trabalhadores entrevistados. Por razões metodológicas, organizamos a análise em dois momentos, um destinado à análise do debate de normas e outro aos usos de si. Embora sejam dimensões indissociáveis, que articulam debate de valores em diferentes perspectivas, a opção seguida procura focalizar particularidades desses aspectos no dizer dos trabalhadores.

Os discursos analisados resultaram de duas perguntas. De cada pergunta foram selecionados dois segmentos para a análise, totalizando quatro recortes discursivos. Os dois primeiros focalizam a análise do debate de normas, e os outros dois, a análise dos usos de si. Para a análise dos discursos, visando acessar aspectos do debate de normas e dos usos de si da atividade de trabalho, baseamo-nos na perspectiva dialógica da linguagem, em especial em noções como tom valorativo, relação eu/outro e vozes discursivas.

Passamos a seguir à análise dos discursos selecionados, considerando que, na tensão entre o refletir e o refratar, o dito e o não dito, emergem relações dialógicas, 
relações de sentido, importantes para a produção de conhecimento sobre a atividade laboral na empresa em pauta.

\subsection{Da análise do discurso}

\subsubsection{Sobre o debate de normas}

As normas estão presentes no nosso cotidiano, no convívio social, porém sempre somos convocados a fazer escolhas e a retrabalhá-as. É, nessa direção, que o trabalho não pode ser considerado como uma simples aplicação de normas e de procedimentos, mas sim como um debate de normas (TELLES, ALVAREZ, 2004). Na atividade de trabalho, diante das infidelidades do meio e da singularidade de cada situação, as renormalizações são permanentes, não sendo possível repetir uma tarefa, uma prescrição. Sendo assim, um debate permanente de normas ocorre na concretização da atividade, em que o trabalhador faz reapreciações, julga os procedimentos, os objetos de trabalho, num vaivém contínuo entre o "micro do trabalho e o macro da vida social cristalizada, incorporada nessas normas” (SCHWARTZ, 2011, p. 33).

Especificamente sobre o debate de normas, analisamos os dois primeiros excertos, que se encontram nas respostas dadas por dois entrevistados, à seguinte questão:

(i) Há algum regulamento na empresa, formalizado ou não, que especifique as funções e atribuições de quem desenvolve tua atividade de trabalho? Recebes orientações de como deves exercer tua atividade?

Na primeira sequência analisada, o trabalhador - a quem foi dado o nome fictício de Luís Felipe $^{5}$ - afirmou que as regras das empresas são iguais, mas, paradoxalmente, ele acaba admitindo que precisa constantemente adaptá-las, transformá-las, devido às mudanças diárias. Percebemos, no recorte discursivo seguinte, a presença do debate de normas. Este funcionário ressalta a figura de um superior que orienta seu trabalho. ${ }^{6}$

Segmento (a) - Luís Felipe:

Não... só aí só o supervisor mesmo... né... o supervisor que... ele te coordena e deu... diz o que tem que fazer e o que não tem que fazer... isso diariamente muda... né... porque às vezes é uma coisa às vezes é outra... não é... não é... uma coisa assim... mas... mas é assim mesmo... as regras que tem são essas... acho que as normas de quase todas as empresas são igual... mais ou menos parecida assim... muda alguma coisa... pоиса coisa...

Ao analisarmos as escolhas linguísticas e o tom valorativo do discurso do segmento (a), observamos que, para o trabalhador, o meio é dinâmico, sendo preciso reconhecer as novas situações ("porque às vezes é uma coisa às vezes é outra”); entretanto, se as normas são semelhantes, quase iguais ("mais ou menos parecida assim"; "acho que as normas de quase todas as empresas são igual”), como lidar com isso? O papel do supervisor para este sujeito é o de estabelecer o prescrito, o de dizer o que se deve ou não fazer, ou seja, a norma vem de fora, é dita por alguém, que ocupa uma posição hierárquica mais elevada. Mesmo assim, ao afirmar que "isso diariamente muda", também o papel do supervisor varia ou o funcionário é quem precisa adaptar as normas ao dia a dia? É como se a responsabilidade das renormalizações também recaísse sobre o outro, no caso, o

\footnotetext{
${ }^{5}$ Foram utilizados nomes fictícios para preservar a identidade dos participantes da pesquisa.

${ }^{6}$ Para as transcrições, foram seguidas as orientações de Preti (1999).
} 
supervisor, que o entrevistado reforça pela repetição do substantivo que o nomeia ("supervisor") e pelo intensificador "mesmo". O trabalhador, em interlocução com a entrevistadora, constitui-se na relação dialógica com o outro (no caso o supervisor e o ambiente laboral). Dando a impressão de que a atividade de trabalho é algo simples no início do enunciado ("ele te coordena e deu... diz o que tem que fazer e o que não tem que fazer”), o trabalhador reconhece a mudança como algo constitutivo da prática laboral, ao enunciar "isso diariamente muda... né... porque às vezes é uma coisa às vezes é outra”, o que aponta para as infidelidades do meio.

Ainda com relação a normas, considerando as respostas dadas à pergunta citada anteriormente, é possível observar que os trabalhadores, em princípio, não as reconhecem como tais, como se regulamentos não existissem. A partir do momento em que a pesquisadora provoca o dizer do entrevistado, acabam surgindo pistas discursivas que remetem a normas. Notamos que, por não serem explícitas, claramente nomeadas, o trabalhador demonstra uma certa dificuldade de identificar as normas e de reconhecê-las como regras e/ou regulamentos. Sabemos, entretanto, que, na realização das atividades laborais, alguns prescritos são observados, mesmo que o trabalhador não tenha essa percepção. Se assim não fosse, seria necessário criar constantemente um novo modo de agir a cada situação, o que é inviável.

No trecho a seguir, extraído da entrevista ao funcionário nomeado Guilherme, observamos a exposição de uma sequência de ações relativas à atividade realizada.

Segmento (b) - Guilherme:

É mais o menos assim... tu vai aprendendo com o tempo... então te explicam assim... ah o que .... qual é a prioridade? oh... separar pedidos que são das vendas interna... o que que é as venda interna? Pelotas e Colônia... então quando chegava ( ) o material e a quantidade... então tu só pegava... o... a a nota e começava a separar o material... o que que é? a gente chama norma de separar por... a ordenação de separar por ordem né... primeiro vamo separar as vendas internas depois separar as vendas externa... manter as gavetas sempre com... cheias... com material... sempre fazer levantamento nunca deixar as gaveta vazia... né?... tá sempre bem limpo... né?

Neste excerto, percebemos que Guilherme estabelece um diálogo consigo mesmo, ao incorporar perguntas e respostas no seu próprio enunciado ("qual é a prioridade? oh... separar pedidos”). Ecoam diversas vozes discursivas: a do próprio sujeito que (se) interroga (“qual é a prioridade?”; “o que é que é as venda interna?”; “o que é que é?”), a de quem responde e pede confirmação ("nunca deixar as gaveta vazia... né?”), a de quem explica como se fosse um supervisor/orientador/colega mais experiente ("primeiro vamo separar as vendas internas depois separar as vendas externa”). O discurso do outro é observado desde o início do dizer do trabalhador ("então te explicam assim”), como a indicar que os protocolos, as normas antecedentes, foram apresentados por alguém.

Além disso, percebemos que, por meio das palavras, o entrevistado intervém no agir como se ele mesmo estivesse interessado em explicar a forma como se aprende, como se ensina, não apenas à pesquisadora, mas talvez mais a si mesmo: "qual é a prioridade? oh... separar pedidos que são das vendas interna... o que que é as venda interna? Pelotas e Colônia...”. O diálogo entre o trabalhador e a prescrição (dita por alguém ou por ele mesmo) parece negociar um saber através do esquema pergunta-resposta: “o que que é? a gente chama norma de separar por... a ordenação de separar por ordem né... primeiro vamo separar as vendas internas depois separar as vendas externa... manter as gavetas sempre com... cheias... com material...”.

A verbalização do trabalho por Guilherme remete à explicação de Faïta (2007, p. 167) sobre a relação entre linguagem e ação: “dizer, expressar-se por meio de linguagem é, 
ao mesmo tempo, agir: é também e, sobretudo, agir sobre as pessoas; é enfim, manipular, de maneira simbólica, objetos reais”. Dizer, para o linguista, “é intervir nas relações reais entre as pessoas, com palavras [...] que são, de algum modo, uma representação, uma contrapartida, uma imagem, uma imagem sonora”. No discurso em análise, o trabalhador enumera suas ações, o que se pode observar pelas escolhas linguísticas: como o emprego do infinitivo ("separar”, "manter”, “deixar”), de advérbios ("sempre”, “nunca”) e de elementos que ordenam sequencialmente as ações ("primeiro”, “depois”). A linguagem do trabalhador dá pistas da renormalização feita por ele dos protocolos que provavelmente tomou conhecimento quando da imersão na atividade de trabalho. No debate com as normas antecedentes, através de seu enunciado, Guilherme organiza o fazer, demonstrando, nas sequências de ações, como sua atividade se realiza.

As negociações que se fazem necessárias entre as normas antecedentes, reguladoras do fazer, e as renormalizações, decorrentes da inscrição do sujeito na atividade, exigem uso de si, do trabalhador (SCHWARTZ, 2007, p. 196, grifo do autor): o uso de si constitui-se sempre numa "dualidade às vezes simples e ao mesmo tempo muito complicada" porque envolve sempre "o uso de si 'por si" e 'pelos outros"” e é por isso que "todo trabalho é problemático - problemático e frágil - e comporta um drama”.

Para tratar da dinâmica entre uso de si por si e pelo outro de que os sujeitos lançam mão para gerir as infidelidades do meio, na indissociável relação com o debate de normas, passamos à análise desses usos.

\subsubsection{Sobre os usos de si}

$\mathrm{Na}$ atividade laboral - com suas variabilidades, imprevisibilidades, complexidades, o trabalhador precisa encontrar saídas, escapes, novos rumos. Para isso, ele busca ora em si mesmo ora nas normas e/ou vozes de outros - colegas, supervisor etc. - um caminho para a resolução dos problemas que vão surgindo no dia a dia. Emergem assim tensões entre usos de si por si e pelo outro, fazendo fluir saberes, recursos, experiências e valores nas vivências inantecipáveis do cotidiano (SCHWARTZ, 2007).

No que tange às infidelidades do meio, elas aparecem refletidas e refratadas nos discursos dos entrevistados, como no caso de falta de pessoal, de interações problemáticas com colegas, de falhas da engrenagem e de condições e exigências do trabalho. São esses aspectos que analisamos nos dois excertos que seguem, o primeiro de Guilherme e o segundo de Luís Felipe, em resposta à seguinte questão:

(ii) No teu cotidiano de trabalho, quando aparecem problemas a serem enfrentados, como lidas com essas situações?

Observamos no discurso de Guilherme, segmento (c), a ênfase dada à falta de pessoal, bem como à preocupação em não atender às demandas do trabalho.

Segmento (c) - Guilherme:

( ) eu fico um pouco assim triste que podia ter mais funcionários no depósito lugar onde eu trabalho... porque às vezes... às vezes é fraco... mas às vezes é muita correria então a gente não consegue atender todos... todos os vendedores não consegue atender todas as notas assim... às vezes não consegue atender a supervisora... às vezes não dá... quando tá fraco o movimento tudo bem mas às vezes é muito corrido... o problema maior assim é a falta de funcionários...

Olha... na parte do balcão eu não tenho nenhuma queixa ... nenhuma queixa porque os guris do balcão são muito dedicados... então a metade das vendas da loja é os guri 
do balcão... eles superam televendas... eles superam vendedores externos... então são dedicado... tá... eu acho que eles podiam ter um pouquinho mais de paciência porque a gente tá com falta de funcionário... então às vezes tem três com quatro vendedores pedindo material e eu sou só um... aí ( ) atendo outro... aí quando saiu vou lá atendo outro... aí fica... e o cliente tá na frente ( ) um pouquinho só da.... um pouquinho de paciência... às vezes fica com cara amarrada... mas é que eu sou sozinho... o outro até me ajuda quando ele tá... mas todos os dias ele tem entrega pra fazer...

A avaliação que depreendemos nessa fala de Guilherme, sobre o problema de escassez de pessoal no setor da empresa estudado, assinala um tom emotivo ("eu fico um pouco assim triste"), sinalizado pelo adjetivo "triste", que ele tenta amenizar com "um pouco assim”. No segmento (c) focalizado, observamos, através de pistas discursivas, como o trabalhador justifica sua tristeza, reforçando a necessidade de mais funcionários não só como uma possibilidade, uma expectativa, no início um pouco mais sutil ("podia ter mais funcionários”), mas também como uma urgência, explícita, no final do enunciado (“o problema maior assim é a falta de funcionários”). Mesmo que o sujeito dialógico amenize essa precisão, empregando reiteradamente o modalizador "às vezes” (seis ocorrências) para referir-se a ela em alguns momentos, o não atendimento a "todos os vendedores" e a "todas as notas” revela certa angústia pelo fazer não realizado.

No trecho "às vezes é fraco... mas às vezes é muita correria”, percebemos um tom valorativo que indica a variabilidade das situações de trabalho, dando ênfase aos momentos que exigem mais rapidez. Quando Guilherme repete o enunciado "não consegue atender", apontando para a incapacidade de atender às múltiplas demandas de sua atividade ("não consegue atender todos... todos os vendedores não consegue atender todas as notas assim... às vezes não consegue atender à supervisora... às vezes não dá”), o trabalhador reitera a polivalência que seu labor requer bem como a sua impossibilidade de atender a essa multiplicidade de tarefas. Diante das dificuldades elencadas pelo funcionário, percebese a tensão entre o uso de si por si, a sua forma de lidar com o impasse, e o uso de si pelo outro, no que se refere à pressão de situações com muitas demandas simultâneas, que exigem mais funcionários.

$\mathrm{Na}$ sequência do dizer, observamos que Guilherme avalia positivamente o comportamento dos vendedores internos ("os guris do balcão são muito dedicados”) e exalta a sua importância no bom desempenho das vendas da empresa na comparação com outros setores ("metade das vendas"; "eles superam televendas"; "eles superam vendedores externos”). Em seguida, entretanto, percebemos uma mudança de valoração no discurso do trabalhador, ao sugerir que tais vendedores precisariam de mais paciência ("podiam ter um pouquinho mais de paciência”), já que se sente pressionado pela escassez de funcionários em seu setor (“a gente tá com falta de funcionário”). Na verbalização do seu fazer, o trabalhador deixa pistas discursivas da tensão entre o uso de si por si e pelos outros, como é o caso de precisar atender várias pessoas ao mesmo tempo e não conseguir dar conta disso, sendo só um (“eu sou só um”; “eu sou sozinho”): “às vezes tem três com quatro vendedores pedindo material e eu sou só um... aí [ ] atendo outro... aí quando saiu vou lá atendo outro". Essa fala sobre a própria atividade em relação ao(s) outro(s) traz à tona aspectos da dramática do uso de si, em especial a perspectiva do trabalhador sobre o seu fazer.

A partir dos acentos de valores postos em circulação no discurso de Guilherme, que revelam o conflito entre usos de si, pergunta-se: Como atender às demandas da atividade laboral, se o meio (a empresa) não lhe dá as condições que julga necessárias para isso? Pela verbalização do trabalhador, percebemos um sujeito angustiado, um corpo-si que se debate entre os pedidos dos colegas, que também têm a necessidade premente de atender 
aos clientes no balcão, e a falta de pessoal. É um trabalhador que gostaria de realizar a atividade que julga importante no espaço laboral em que está inserido, mas não consegue. Embora tente justificar sua atitude e a dos colegas, seu sentimento de impotência predomina.

No movimento dialógico do discurso de Guilherme, observamos índices que apontam para a alteração crescente do seu posicionamento, variando de elogios aos colegas (com repetições como "nenhuma queixa"; "muito dedicados") ao pedido de paciência devido ao fato de estar sozinho no setor. Sabemos que, ao verbalizar, o sujeito se responsabiliza pelo seu dizer, e não há álibi capaz de desresponsabilizá-lo por esse ato. Sendo assim, no momento irrepetível da enunciação, no desenvolvimento do dizer, sua linguagem evoca aspectos da complexidade da situação. O acentuado tom emotivo-volitivo aparece de forma inequívoca, como um grito de socorro deste trabalhador que parece se ver como alguém incapaz de realizar as atividades que a empresa, na figura de seus colegas, clientes, supervisor, solicita.

O discurso de Guilherme é atravessado por vozes dissonantes e contraditórias, que, colocando em relação o eu e o outro, revelam o ponto de vista do sujeito dialógico em relação a suas próprias cobranças, vivências, experiências no trabalho, via linguagem sobre o trabalho. São valores postos em cena que refletem e refratam aspectos da dramaticidade de usos de si da atividade desenvolvida.

Além do problema da falta de pessoal, analisado nos enunciados de Guilherme, observamos, na fala de Luís Felipe, outro problema que também reverbera a questão de usos de si: a falha da tecnologia.

\section{Segmento (d) - Luís Felipe:}

Não... não... né... ah... xi... aquele tipo de coisa assim ... bah... mas o sistema diz que tem e tu tá dizendo que não tem () o sistema deu uma pane no sistema e tava dando um horror... não deu nada certo... e vem o colega... não... mas o sistema tem... vai procurar... mais eu já olhei ... a primeira coisa tem que olhar no estoque... depois na loja... né... vim na loja conversei com o Fernando... oh... Fernando... tá acontecendo isso... isso... primeiro passei pra Sílvia.. né... a Sílvia e o Fernando resolveram... aí no final eles viram que o sistema tava dando algum erro... hoje o sistema não sei como se ajeitou hoje o troço... meio complicado a coisa... mas ontem tava meio pesado... mas tem que saber relevar... tem que saber relevar... talvez num outro...

Ao verbalizar sobre um problema de pane no sistema da empresa, podemos entender como o trabalhador, através da sua enunciação, avalia as consequências daí advindas ("o sistema deu uma pane no sistema e tava dando um horror... não deu nada certo”). Neste segmento, percebemos também que a cobrança dos colegas é referida, embora de maneira mais sutil, se a compararmos com a angústia que emerge no discurso analisado do outro funcionário (Guilherme). No dizer de Luís Felipe, a tensão de uso de si por si e uso de si pelo outro pode ser observada na tentativa de resolver o problema instaurado ("mas o sistema diz que tem e tu tá dizendo que não tem", "a primeira coisa tem que olhar no estoque... depois na loja... né") e na delegação ao outro ("vim na loja conversei com o Fernando... oh... Fernando... tá acontecendo isso... isso... primeiro passei pra Sílvia... né... a Sílvia e o Fernando resolveram”). Nesse embate, vozes diversas trazem indícios de experiências vividas na atividade de trabalho, em que normas e renormalizações são postas em evidência na gestão dos imprevistos que o meio laboral apresenta.

Na relação eu/outro, é possível observar, no discurso em foco, a emergência do confronto entre o trabalhador e o sistema, o trabalhador e outros trabalhadores, o trabalhador e a falha no sistema. O jogo de valores entre o problema vivido ("meio 
complicado a coisa... mas ontem tava meio pesado") e a busca de saída para os impasses da atividade ("tem que saber relevar", duas vezes enunciado) revela um trabalhador com jogo de cintura para lidar com as infidelidades do meio.

Comparando os discursos de Luís Felipe e os de Guilherme, constatamos uma diferença importante, o que deixa claro que o uso de si por si de cada um depende não apenas das características individuais e do contexto em que estão inseridos como também do uso que fazem do outro (uso de si pelo outro). Certamente esse outro (seja o meio, as condições de execução das atividades, os colegas, o supervisor etc.) afeta de maneira distinta cada sujeito, pois, assim como não há duas situações que se repetem, são singulares e únicas também as maneiras de lidar com elas. Guilherme e Luís Felipe fazem diferentes usos de si frente aos problemas que os interpelam na atividade, como a falta de funcionário e a pane no sistema. Nesses usos, cada um, querendo ou não, é responsável por seus atos, sua maneira singular de agir com o outro.

Tais perspectivas são observadas pelas respostas nas entrevistas, criadas como um espaço de reflexão, em que se busca recuperar valores e experiências dos trabalhadores nas/sobre suas práticas laborais. Isso só é possível com uma perspectiva de linguagem que tem como pressuposto a dinâmica relação eu/outro e que não pretende ser um "espelho" da realidade, mas sim construir sentido sobre ela, tendo em vista a singularização do dizer e dos sentidos.

\section{Considerações finais}

Neste artigo, procuramos discutir, a partir dos discursos dos trabalhadores de uma empresa comercial, obtidos em entrevistas individuais, aspectos do debate de normas e dos usos de si na atividade.

Para desenvolver essa reflexão, embasamo-nos na teoria dialógica bakhtiniana, que concebe a linguagem como heterogênea, dinâmica e pluridiscursiva, e nos estudos ergológicos sobre o trabalho, que entendem ser a atividade laboral complexa e reconhecem a importância da análise da linguagem para melhor compreendê-la.

Para verificar aspectos do debate de normas na atividade dos trabalhadores da empresa, perguntamos se havia algum regulamento, formalizado ou não, que especificasse as funções e atribuições de cada um, se havia orientações de como exercer sua atividade. Selecionamos, para a análise deste item, dois segmentos das entrevistas de dois funcionários. Pela análise das respostas apresentadas, constatamos que, em geral, os trabalhadores não reconhecem claramente as normas, talvez por elas não serem explícitas, ou por sentirem, em certos momentos, a ausência de normas (anomia). Se não percebem as normas como tais, os entrevistados, em seus discursos, apresentam diferentes maneiras de lidar com elas. Enquanto Luís Felipe, através de seu discurso, põe a responsabilidade das normas no supervisor, Guilherme apresenta, em sequência ordenada, as ações, que diz serem realizadas no seu trabalho. Assim, a partir dos excertos enunciativos analisados, notamos que os trabalhadores, mesmo que não percebam, estabelecem o debate entre normas antecedentes e renormalizações, quando inscritos na atividade do trabalho.

Sabemos que as normas antecedentes existem, embora não consigam abarcar toda a complexidade, heterogeneidade e flexibilidade do meio laboral, por isso, em cada situação, o indivíduo precisa renormalizá-las, ou seja, singularizar seu modo de agir, fazendo uso de si.

A fim de analisar aspectos dos usos de si para gerir as infidelidades do meio, questionamos os entrevistados sobre os problemas que aparecem no dia a dia laboral e sobre as formas de solucioná-los. Dois segmentos, retirados de duas entrevistas, foram analisados. Os trabalhadores pesquisados demonstraram diferentes formas de lidar com as 
situações de tensão do dia a dia. Enquanto Guilherme se mostra um pouco confuso, inseguro, angustiado, para lidar com as variabilidades e a dinamicidade da atividade que realiza, Luís Felipe parece encontrar um caminho mais tranquilo, visualizando as variabilidades como uma possibilidade de crescimento ou de aprendizado. As infidelidades do meio são percebidas de maneiras diversas, uma vez que cada um faz suas escolhas de acordo com suas vivências, seus valores, seu modo de ser, seus saberes. ${ }^{7}$

Esse embate de normas e saberes relaciona-se ainda aos usos de si que cada trabalhador faz em situação laboral. Eles não são usos estanques, estão sempre em tensão. Ao mesmo tempo em que emprega seus valores, seus saberes, suas experiências, seu modo particular de agir, o sujeito vai buscar no outro as normas, os já-ditos, as condições que o meio oferece, ou seja, há um embate permanente e dramático entre os usos de si.

A partir dessas análises, destacamos características da atividade nesse espaço laboral. Percebemos que se trata de uma atividade complexa, heterogênea, dinâmica, que requer, principalmente, um sujeito flexível, capaz de realizar múltiplas tarefas, com rapidez e agilidade. Como entendemos o trabalho sob a abordagem ergológica, não podemos ignorar as variabilidades do meio e as ressingularizações que cada trabalhador faz no dia a dia. Para isso, o sujeito lança mão de suas competências, conjugando o uso de si por si e o uso de si pelo outro. Sem uma articulação equilibrada entre esses usos e um retrabalho permanente de normas antecedentes e de valores em que o indivíduo possa colocar em debate suas vivências e seus conceitos, sempre provisórios, levando em conta também os valores do coletivo, da sociedade em que está inserido, o trabalho deixa de ser vivível para se tornar uma doença.

Diante das características da atividade laboral no campo estudado, ressaltamos que, num cenário tão dinâmico, heterogêneo, que envolve a complexidade do humano em sua individualidade e em relação ao coletivo e ao social em que está inserido, é importante criar espaços de dizer para que os sujeitos possam, via discurso, refletir sobre o próprio fazer, frente a um interlocutor distanciado do meio laboral. É pela verbalização sobre o trabalho que vozes discursivas são refletidas e refratadas, tecendo conhecimento e reconhecimento da atividade laboral.

Levando em conta a demanda apresentada pela empresa comercial, cujo teor foi especificado como falta de envolvimento do trabalhador com a atividade que realiza, não pretendemos, com este estudo, fornecer nenhuma resposta pronta ou solução mágica para essa problemática. Nossa proposta é que, a partir do espaço que se criou para dar voz ao trabalhador, tenha sido suscitada alguma reflexão e que novos espaços de dizer sejam criados para que as relações dialógicas se concretizem na troca entre os saberes, tanto entre os funcionários dos diversos setores quanto com a gerência. Dessa forma, ao se sentirem valorizados, prestigiados, ouvidos, esses trabalhadores podem envolver-se mais com o que fazem no dia a dia laboral. Ou ainda, o trabalhador, ao olhar para si mesmo, para a sua atividade no ambiente laboral, pode não apenas vincular-se à empresa de modo diferenciado, com mais envolvimento, como também descobrir as suas competências, o seu potencial, para crescer profissionalmente e como pessoa. Os gestores da empresa, por sua vez, com a abertura desse espaço, poderiam também conhecer melhor os trabalhadores e as atividades que desempenham na organização, compreendendo a sua complexidade, sem

\footnotetext{
${ }^{7}$ Verificamos que a diferença de comportamento revelada nos discursos dos dois sujeitos, apresentados na análise quanto ao embate entre os usos de si, pode ser resultante, principalmente, do fato de Luís Felipe ter mais experiência que Guilherme, ou seja, suas vivências em outros trabalhos the possibilitaram concretizar de modo mais equilibrado suas arbitragens, relativizando suas frustrações, lidando melhor com os problemas à medida que vão surgindo. Guilherme, além de apresentar mais insegurança nas suas escolhas, sente-se muito pressionado pelas exigências dos colegas, pelas variabilidades do meio, pela carência de pessoal no setor e pela polivalência de funções que sua atividade requer.
} 
olhar somente para o prescrito, para as normas antecedentes. Ao darem voz aos trabalhadores para críticas e sugestões, os gestores poderiam beneficiar-se com as contribuições advindas das reflexões e debates suscitados pela troca de experiências.

\section{REFERÊNCIAS}

BAKHTIN, M. O autor e a personagem na atividade estética (1920-1930). In: Estética da criação verbal. 1. ed de (1979). 4. ed. Tradução Paulo Bezerra. São Paulo: Martins Fontes, 2006c. p. 3-192.

BAKHTIN, M. O discurso no romance (1934-1935). In: Questões de literatura e de estética: a teoria do romance (1975). Tradução Bernadini et al. 3. ed. São Paulo: UNESP, Hucitec, 1993. p. 71-163.

BAKHTIN, M. O problema do texto na linguística, na filologia e em outras ciências humanas (1959-1961). In: Estética da criação verbal (1979). 4. ed. Tradução Paulo Bezerra. São Paulo: Martins Fontes, 2006b. p. 307-335.

BAKHTIN, M. Os gêneros do discurso (1952-1953). In: . Estética da criação verbal (1979). 4. ed. Tradução Paulo Bezerra. São Paulo: Martins Fontes, 2006a. p. 261-306.

BAKHTIN, M. Os gêneros do discurso (1952-1953). In: Estética da criação verbal (1979). Tradução Maria Ermantina Galvão Gomes Pereira. São Paulo: Martins Fontes, 1992. p. 277-326.

BAKHTIN, M. Para uma filosofia do ato responsável (1920-1924). Tradução Valdemir Miotello e Carlos Alberto Faraco. São Carlos: Pedro \& João Editores, 2010.

BAKHTIN, M. Problemas da poética de Dostoiévski (1929). 2. ed. Tradução Paulo Bezerra. Rio de Janeiro: Forense Universitária, 1997.

BAKHTIN, M.; VOLOCHÍNOV, V. N. Marxismo e filosofia da linguagem: problemas fundamentais do método sociológico na ciência da linguagem. Tradução Michel Lahud e Yara Frateschi Vieira. Original de 1929. 13. ed. São Paulo: Hucitec, 2009.

CLOT, Y. O diálogo em desenvolvimento: M. Bakhtin no trabalho. In: DE PAULA, L.; STAFUZZA, G. (Org.). Círculo de Bakhtin: diálogos in possíveis. Campinas, SP: Mercado de Letras, 2010. p.175-198.

CLOT, Y.; FAÏTA, D. Genres et styles en analyse du travail: concepts et méthodes. Travailler, Revigny-sur-Ornain, n.4, p.7-42, 2000.

DI FANTI, M. G. Linguagem e trabalho: diálogo entre a translinguística e a ergologia. Desenredo, v. 8, p. 309-329, 2012.

FAÏTA, D. A linguagem como atividade: conversa entre Daniel Faïta, Christine Noël e Louis Durrive. Tradução Maristela Botelho França e Maria da Glória Corrêa Di Fanti. In: SCHWARTZ, Y.; DURRIVE, L. (Org.). Trabalho \& ergologia: conversas sobre a atividade humana. Coordenação da tradução e revisão técnica de Jussara Brito e Milton Athayde. Niterói: EdUFF, 2007. p. 167-188.

FAÏTA, D. Análise dialógica da atividade profissional. Tradução e organização: M. G. Di Fanti.; M. França; M. Vieira. Rio de Janeiro: Express, 2005.

FAÏTA, D. Des genres de discours aux genres d'activité. Quelques réflexions à propos de la recherche sur les rapports langage-travail. Calidoscópio, v.1, n.1, p. 117-136, 2003. 
FAÏTA, D. La conduite du TGV: exercices de styles. Champs Visuel, n.6, L’Harmattan, p.122-129, 1997.

FARACO, C. A. Linguagem \& diálogo: as ideias linguísticas do círculo de Bakhtin. São Paulo: Parábola, 2009.

HINZ, J. R.; DI FANTI, M. G. C. A atividade do professor-estagiário de Língua Portuguesa: aprendizagem de gêneros profissionais? Letras, v. 22, p. 55-83, 2012.

MACHADO, B. I. A atividade de trabalho em uma empresa comercial: da importância de espaços de dizer. Tese (Doutorado em Linguística Aplicada) - Programa de PósGraduação em Letras, Universidade Católica de Pelotas, Pelotas, 2012.

NOUROUDINE, A. A linguagem: dispositivo revelador da complexidade do trabalho. In: Souza-e-Silva, M. C. P.; Faïta, D. (Org.). Linguagem e trabalho: construção de objetos de análise no Brasil e na França. Tradução Inês Polegatto, Décio Rocha. São Paulo: Cortez, 2002. p.17-30.

PRETI, D. Análise de textos orais. 4. ed. São Paulo: Humanitas Publicações, 1999.

ROCHA, D.; DAHER, M. C.; SANTANNA, V. L. A. A entrevista em situação de pesquisa acadêmica: reflexões numa perspectiva discursiva. Polifonia. Cuiabá, n. 8, p.161-180, 2004.

SCHWARTZ, Y. A abordagem do trabalho reconfigura nossa relação com os saberes acadêmicos: as antecipações do trabalho. In: SOUZA-E-SILVA, M. C. P.; FAÏTA, D. (Org.). Linguagem e trabalho: construção de objetos de análise no Brasil e na França. Tradução Ines Polegatto e Décio Rocha. São Paulo: Cortez, 2002. p. 109-126.

SCHWARTZ, Y. Conceituando o trabalho, o visível e o invisível. Revista trabalho, educação e saúde. Rio de Janeiro: Fundação Oswaldo Cruz, v.9, supl.1, p.19-45, 2011.

SCHWARTZ, Y. Entrevista. Revista trabalho, educação e saúde, Rio de Janeiro: Fundação Oswaldo Cruz, v. 4, n. 2, p.457-466, 2006.

SCHWARTZ, Y. Trabalho e uso de si. Conversa entre Yves Schwartz, Marcelle Duc e Louis Durrive. Tradução. Ana Heckert e Maria Elisabeth B. de Barros. In: SCHWARTZ, Y.; DURRIVE, L. (Orgs.). Trabalho \& ergologia: conversas sobre a atividade humana. Coordenação da tradução e revisão técnica de Jussara Brito e Milton Athayde. Niterói: EdUFF, 2007. p. 191-223.

SCHWARTZ, Y.; DURRIVE, L. (Org.). Trabalho \& ergologia: conversas sobre a atividade humana. Coordenação da tradução e revisão técnica de Jussara Brito e Milton Athayde. Niterói: EdUFF, 2010.

TELLES A. L.; ALVAREZ, D. Interfaces ergonomia-ergologia: uma discussão sobre trabalho prescrito e normas antecedentes. In: FIGUEIREDO et al. (Org.). Labirintos do trabalho: interrogações e olhares sobre o trabalho vivo. Rio de Janeiro: DP\&A, 2004. p. 63-90.

Recebido em fevereiro de 2013.

Aprovado em abril de 2013. 